\title{
Attitude of judgment and reaction time in estimation of size at a distance
}

\author{
WILLIAM EPSTEIN \\ University of Wiscomsin-Madison, Madison, Wisconsin 59706
}

and

KRISHAN D, BROOTA

University of Delhi, Delhi, India

\begin{abstract}
Experiment I obtained scalar (absolute) size estimates under full cue conditions for rectangular standards that were presented at distances ranging from 1.22 to $3.05 \mathrm{~m}$. Size-estimate reaction times increased linearly with increasing viewing distance. Reaction times for distance estimation were the same at all distances. Experiment II obtained size estimates over distances ranging from 1.22 to $5.49 \mathrm{~m}$ under objective and phenomenal size-estimation instructions. Only objective size-estimate reaction times increased with distance. Phenomenal size estimates were faster then objective estimates and were the same for all viewing distances. It was concluded that the cognitive operations involved in objective size estimation were responsible for the effects obtained in Experiment I and the similar findings reported in earlier studies by Broota and Epstein (1973).
\end{abstract}

In earlier experiments employing a same-different task and a recognition-memory-type task, Broota and Epstein (1973) found that under full-cue conditions the time required for correct size jud gments increased linearly as the viewing distance increased. By holding visual angle constant for the different viewing distances, it was possible to show that he reaction time for size estimation was not dependent on processing visual angle. Nor was the size-estimation reaction time dependent on the time to process differences in distance, since the reaction time for distance estimation did not vary as the distance extent varied. Experiment $I$ in the present series was designed to demonstrate the dependence of size-estimation reaction time on viewing distance in a situation which emphasized the estimation of scalar (absolute) size rather than relative size. Experiment II was designed to test a hypothesis to account for the findings reported by Broota and Epstein (1973) and confirmed in Experiment I.

\section{EXPERIMENT I}

\section{Method}

Subjects. The subjects were 10 undergraduates at the University of Wisconsin with no previous experience in size-judgment experiments. All subjects had normal or corrected vision.

Stimuli. The stimuli were four white cardboard rectangles. $5.1-12.7 \mathrm{~cm}$ in height and $2.5 \mathrm{~cm}$ in width. Each one was mounted separately on a metal $\operatorname{rod}(.3 \mathrm{~cm}$ in diam) with its long dimension

This work was done at the University of Wisconsin with support from the University of Delhi under the Faculty Exchange Program of Delhi University and funded by the Ford Foundation and at the University of Deliti with support from the ICSSR. New Dethi. upright. The center of each rectangle was at a constant height aligned with the subject's line of sight. The supporting rod was inserted into a $5.1 \times 5.1 \mathrm{~cm}$ metal base. The stimuli were presented $1.22,1.83 .2 .44$, or $3.05 \mathrm{~m}$ from the subject. Accordingly, the $5.1 \mathrm{~cm}$ rectangle at $1.22 \mathrm{~m}$, the $7.5 \cdot \mathrm{cm}$ rectangle at $1.83 \mathrm{~m}$, the $10.2 \mathrm{~cm}$ rectangle at $2.44 \mathrm{~m}$, and the $12.7-\mathrm{cm}$ rectangle at $3.05 \mathrm{~m}$ subtended the same visual angle, $2^{\circ} 23^{\prime}$ of arc.

Apparatus. The apparatus consisted of three units: a display unit, a four-digit electronic counter/timer, and a response unit. The tloor of the display unit was $6.3 \mathrm{~m}$ long and $90 \mathrm{~cm}$ wide and was constructed of unpainted sheets of plywood. An upright flat black wooden panel at the far end served as the backdrop for the display. Another upright panel at the near end was equipped with a protruding padded viewer providing a $12.70 \times 7.62 \mathrm{~cm}$ viewing aperture. Normal fluorescent room illumination prevailed. A fall-type shutter was used to occlude the subject's view of the stimuli. When the shutter was released, the viewing window was cleared, allowing an unrestricted view of the floor and background as well as the targets. The response unit consisted of one light-touch push button, which was mounted below the viewing window on an extension where the subject could conveniently rest his forearm. The timer was actuated by the fall of the shutter and stopped by the push button response. Reaction time was measured in milliseconds.

Procedure and Design. Each subject provided verbal estimates in feet and inches of size and distance. The size estimates and distance estimates were secured on different days, and all of the estimates of one type were collected before the other estimates were solicited. Five subjects provided size estimates first and five provided distance estimates first. The following is a description of the procedure for securing size escimates. The procedure for securing distance estimates was identical in all respects except that verbal estimates of distance were solicited.

Each subject was individually tested. At the beginning of each session. the experimental task was explained. The subject was required to repor an estinlate of the objective size of the target in inches and sinultaneously to press the response button. No taniliarization with the stinuti was given outside the experimental exposures. nor was the subject inforned about the number of ditterent strmulis. However, to reduce the between-subject variability in using the scale and to encourage judgments of 
objective size. the subject was shown a standard foot rule and was reminded of the objective length of the standard units. This training was introduced as part of the preliminary instructions.

Each of the four rectangles was presented one at a time at one of the four distances from the subject. providing 16 combinations of size and distance. The subjects were tested on 3 successive days, at the same time of the day. The first day was devoted to practice involving 96 trials. six repetitions for each of the 16 combinations of size and distance. in random order. The subjects were also given enough practice. on the first day. in pressing the response button at the onset of the verbal response so that the motor response was synchronized with the verbal report. On the subsequent days. each subject was given $\%$ trials in each experimental session. Thus. for each combination of size and distance, each subject gave 12 responses. giving a total of $192(12 \times 16)$ responses in two experimental sessions. Order of presentation was random. A rest pause of $5 \mathrm{~min}$ was provided midway in each session.

The instructions encouraged the subject to respond as rapidly as possible without making errors. He was also told that the width of all the targets was the same and that width should be disregarded. Before releasing the shutter, a ready signal was given and the subject was required to place the forehead on the padded extension of the rieuing window and position the index finger (preferred hand) on the push button. The shutter was manually reset after each response. and the stimulus was replaced whether a change was called for by the random sequence or not.

\section{Results}

Since the results showed no effects of the order in which the size and distance judgments were solicited. this factor will be ignored. The results reported below are based on the performances of all 10 subjects.

Size estimates. In Figure 1. the reaction time for

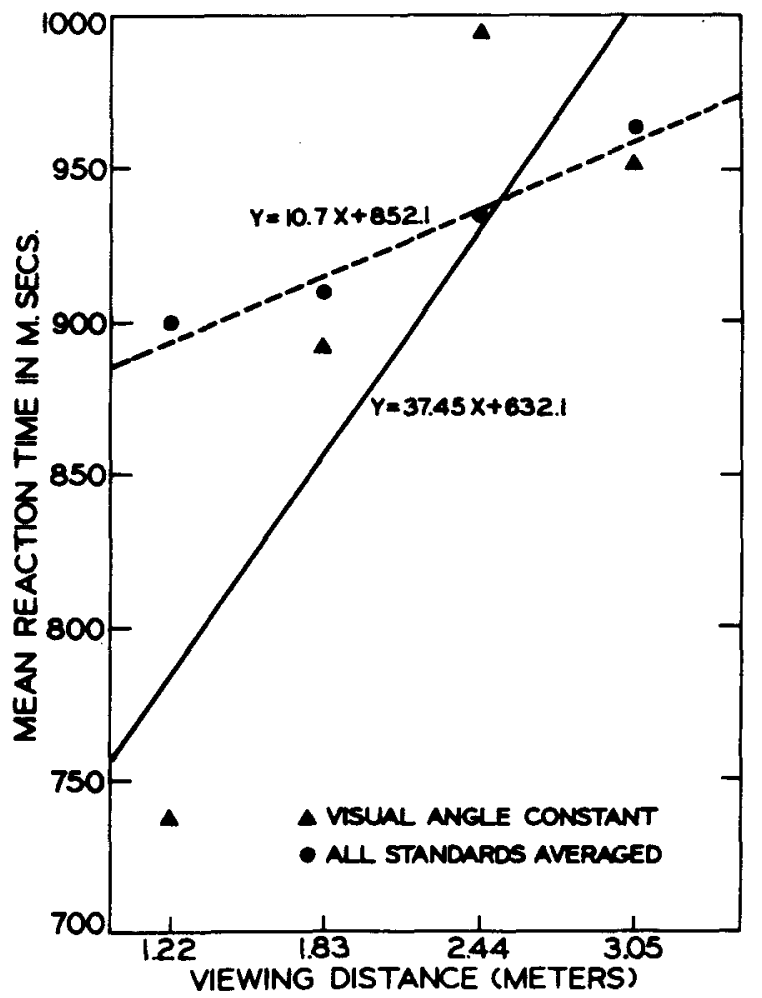

Figure 1. Mean reaction time for size estimates as a function of egocentric distance for all standards averaged and for a subset of standards which subtended the same visual angle at the four distances. the four sizes have been averaged and plotted as a function of distance. Also shown in Figure 1 is the line fitted by least squares and its equation. Figure 1 shows that size-estimation reaction time was a linear increasing function of egocentric distance. Analysis of variance showed significant reaction-time differences associated with egocentric distance, $F(3,27)=2.97$. $p$ $=.05$. The linear component was significant. $F(1.9)$ $=67.58 . \mathrm{p}<.01$, and accounted for $96.64 \%$ of the variance. The standard error of the slope was 1.09 . The Size by Distance interaction was not significant. Nor was there a significant correlation between judgmental error and RT at any of the four distances.

Figure 1 also presents reaction time as a function of egocentric distance for the four targets that subtended the same visual angle. The trend for this subset $[F(3.27)=6.26, p<.01]$ was similar to the trend exhibited by the averages for all the standards. Both the linear $[F(1.27)=13.31, p<.01]$ and the quadratic $[F(1.27)=4.29 . p<.05]$ were significant. The linear component accounted for $70 \%$ of the variance. and the quadratic component for $25 \%$. The standard error of the slope was 11.88. In both cases. reaction time increases with viewing distance despite the fact that the average visual angle was inversely related to distance for the averages of all standards and was constant for the subset. The divergence between the two functions at the $3.05-\mathrm{m}$ distance may be due to an anchoring effect associated with the largest rectangle which is the only target that contributed to the reaction time for the $3.05-\mathrm{m}$ distance in the constant visual angle subset.

The mean size estimates averaged over the four presentation distances were $5.03,8.08,10.46$, and $13.97 \mathrm{~cm}$ for the $5.1-.7 .5-, 10.2-$. and $12.7-\mathrm{cm}$ rectangles. respectively. The size estimates averaged over the four sizes were 9.04 .9 .50 .9 .47 , and $9.50 \mathrm{~cm}$ for the 1.22-. 1.83-. 2.44-. and 3.05-m distances, respectively. The objective average size was $8.9 \mathrm{~cm}$. Under the prevailing viewing conditions, accuracy and size constancy were high.

Distance estimates. The mean reaction time was 903. 869. 1.002. and $922 \mathrm{msec}$ for the 1.22-. 1.83-, 2.44-. and 3.05-m distances. respectively. Analysis of variance failed to show significant differences. The slope of the reaction-time function was essentially zero. Distance-estimation reaction time was notably more variable than size-estimation reaction time. The error variance for distance estimation was almost nine times as great as the error for size estimation; the standard error of the mean for distance-estimation reaction time was three times as great as the standard error for size estimation.

The average estimates of the 1.22-. 1.83-. 2.44-. and $3.05-\mathrm{m}$ distances were. respectively, 0.83 .1 .42 . 2.07 . and $2.70 \mathrm{~m}$. Distances were regularly underestimated. The percent of underestimation for the 1.22-. 1.83-. 2.44-. and $3.05-\mathrm{m}$ distances was $32.5 \% .21 .6 \% .15 \%$, and $11 \%$. 


\section{Discussion}

Experiment I extended the findings of the earlier studies by showing that the linear increasing function relating processing time for size judgment to egocentric distance holds for estimates of absolute size as well as estimates of relative size. In agreement with the earlier studies, we were unable to adduce any evidence that differences in visual angle or registration of distance were involved in the differences in reaction time for size estimation. It could be argued that the reaction time reflects the duration of the combinatorial stage, but it is difficult to see why the algorithm involving visual angle and registered distance should require different times for its application as distance is varied.

If the reaction-time differences are not attributable to the mandatory processes that are alluded to in the size-distance algorithm, perhaps they are due to optional processes that are actuated by the subject. In the literature on size perception, instructions that affect observation attitude have long been recognized to be effective means for triggering optional cognitive operations (Carlson, 1960, 1962; Carlson \& Tassone, 1967; Epstein, 1963; Epstein, Park, \& Casey, 1961). Accordingly, it may be instructive to ask whether observation attitude could be responsible for the - reaction time findings.

The instructions administered to the subject solicited estimates of objective size ("objective" attitude) in contrast to estimates based on immediate impressions ("phenomenal" attitude). The distinction between phenomenal (immediately perceived) and objective properties is familiar to most observers from the conınonplace experience of an object at a great distance appearing to be small although the object is known to be large. In many instances, in order to respond to an inquiry about objective size, cognitive deliberations must be introduced. If the object is readily identified, then remembered size, i.e., the perceived size of the object when it is viewed nearby, may be referenced. In the case of an object that does not have a know'n size, e.g., an unfamiliar hill or a cardboard square, familiar size may enter into the deliberations in a different way. The interrogation about the objective size of the unfamiliar object may be answered by identifying a familiar size object which would have the same apparent size as the unfamiliar object were it placed at the distance of the unfamiliar object. If the time required to complete this mental operation depends on viewing distance, analogous to the dependence of "mental rotation" on the degree of physical rotation (Shepard \& Metzler, 1971; Cooper \& Shepard, 1973), an account of the size-estimate reaction times is suggested.

In Experiment I as well as in the studies by Broota and Epstein (1973), reaction time for size judgment may have increased with distance because, with increasing distance, the cognitive operations involved in the derivation of objective size require more time. This account leads to three predictions. (1) If the subject is induced to adopt a phenomenal attitude, the slope of the function relating reaction time for size judgment to viewing distance should not differ from zero. (2) The reaction time for objective size judgments should be longer than reaction time for phenomenal size judgments. (3) Attitude of observation and viewing distance should interact. The difference between the reaction time for objective and phenomenal judgments should increase as viewing distance increases.

\section{EXPERIMENT II}

The purpose of Experiment Il was to compare reaction time for size estimates as a function of viewing distance under the objective and phenomenal attitudes of judgments.

\section{Method}

Subjects. The subjects were 16 members of the university community at the University of Delhi. All had normal or corrected vision.

Stimull. Since the standard stimuli in Experiment I were rectangles of constant width, it is possible that the subjects were making height-to-width ratio judgments rather than absolute-size judgments. With this consideration in mind, the rectangles were replaced by squares in Experiment II. The test stimuli were eight white cardboard squares ranging in size from $2.54 \mathrm{~cm}$ to $11.43 \mathrm{~cm}$ on a side in $1.27 \mathrm{~cm}$ intervals. The stimuli were presented at distances of $1.22,1.83,2.44,3.05,3.66,4.27,4.88$, and $5.49 \mathrm{~m}$. A set of tour rectangles. the stimuli of Experiment 1 , were used in the practice stage.

Procedure and Design. Only size estimates were obtained. Eight subjects received objective size-judgment instructions identical to those administered in Experiment $I$ and in the earlier study by Broota and Epstein (1973). Eight subjects received phenomenal size-judgment instructions, which stressed that responses should be based on the immediate appearance of size without concern for objective size. None of the subjects received information about the true sizes and distances of the stimuli, nor was error feedback provided to either group.

Each subject participated in five sessions on 5 successive days. The first day was devoted to practice with the task of size estimation and concurrent button pushing. Each of the four rectangular stimuli was presented three times at each of the eight distances. Days 2.5 were devoted to the experimental trials. On each day. each of the eight squares was presented at each of the eight distances so that the total number of experimental trials was 256 . A different random order of trials was used on each day.

\section{Results}

The principal results are shown in Figure 2, which presents the mean reaction time for size estimation as a function of viewing distance and instructions. It is obvious that reaction time for phenomenal instructions (mean $=235 \mathrm{msec}$ ) was significantly faster than reaction time for objective instructions (mean $=582 \mathrm{msec}$ ). It is also clear from Figure 2 that the reaction time for objective size estimates increased as viewing distance increased. The linear component $[\mathrm{F}(1.49)=153.50 . \mathrm{p}<.001]$ accounted for $88.88 \%$ 


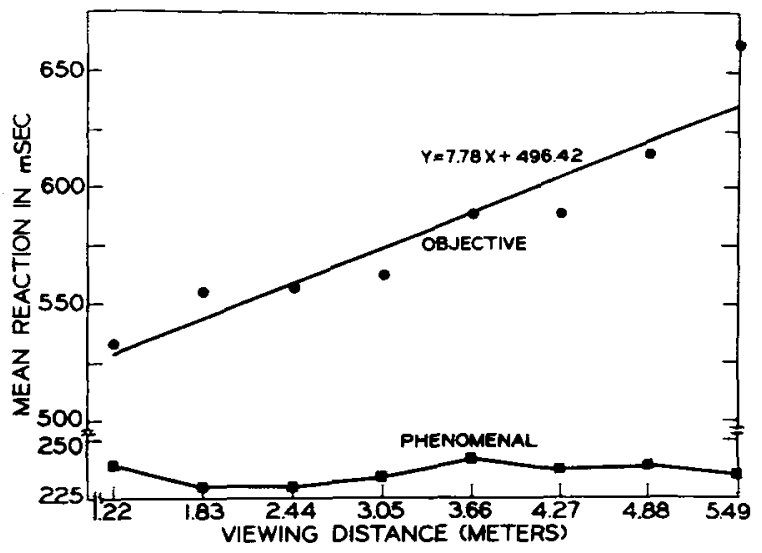

Figure 2. Mean reaction time for size estimates as a function of egocentric distance for objective and phenomenal size-judgment instructions.

of the variance, and the quadratic component $[F(1,49)=10.6 . p<.01]$ accounted for $6.16 \%$. The standard error of the slope was 1.08. The Size by Distance interaction was not significant. Correlations computed between judgmental error and reaction time at each distance showed no systematic relationship. In contrast with the data for the objective instructions, the phenomenal size estimates were unaffected by viewing distance, having a slope of zero.

Table 1 shows the verbal size estimates. Discrimination of size was good, as would be expected under the full-cue conditions that prevailed, and there was little variation in judged size as a function of distance. There was a consistent tendency for size estimates under objective instructions to be higher than the estimates under phenomenal instructions, and the difference between the two types of estimate

Table 1

Mean Size Estimates (cm): (a) Averaged for All Distances and (b) Averaged for All Sizes

\begin{tabular}{|c|c|c|c|c|c|}
\hline \multirow{2}{*}{$\begin{array}{l}\text { Objec- } \\
\text { tive } \\
\text { Size }(\mathrm{cm})\end{array}$} & \multicolumn{2}{|c|}{$\begin{array}{l}\text { (a) } \\
\text { Size Estimates }\end{array}$} & \multirow{2}{*}{$\begin{array}{c}\text { Egocentric } \\
\text { Distance } \\
\text { (m) }\end{array}$} & \multicolumn{2}{|c|}{$\begin{array}{l}\text { (b) } \\
\text { Size Estimates }\end{array}$} \\
\hline & $\begin{array}{l}\text { Pheno- } \\
\text { menal }\end{array}$ & $\begin{array}{l}\text { Objec- } \\
\text { tive }\end{array}$ & & $\begin{array}{l}\text { Pheno- } \\
\text { menal }\end{array}$ & $\begin{array}{l}\text { Objec- } \\
\text { tive }\end{array}$ \\
\hline 2.54 & 2.31 & 2.36 & 1.22 & 6.42 & 6.59 \\
\hline 3.81 & 3.40 & 3.71 & 1.83 & 6.53 & 6.93 \\
\hline 5.08 & 4.57 & 4.88 & 2.44 & 6.46 & 6.89 \\
\hline 6.35 & 5.61 & 6.43 & 3.05 & 6.31 & 6.93 \\
\hline 7.62 & 6.93 & 7.54 & 3.66 & 6.31 & 6.91 \\
\hline 8.89 & 8.23 & 8.84 & 4.27 & 6.36 & 6.92 \\
\hline 10.16 & 9.19 & 10.03 & 4.88 & 6.13 & 6.79 \\
\hline 11.43 & 10.39 & 11.05 & 5.49 & 6.08 & 6.86 \\
\hline
\end{tabular}

increased with viewing distance. These trends are consistent with the results reported in the size-distance literature.

\section{CONCLUSIONS}

When phenomenal size estimates were solicited, the time to estimate size did not vary with viewing distance. Plainly, the explanation of the data of Experiment I and the earlier report by Broota and Epstein (1973) is to be found in a feature of the process associated with the objective size-estimation attitude. The account of the process that was proposed at the conclusion of Experiment I was speculative, and alternatives can certainly be devised. As one alternative, it may be proposed that the differences between the reaction times may be localized in the decision stage. Objective instructions implicitly require a veridicality assessment which may add to the reaction-time intercept. If confidence in veridicality decreases as distance increases, this could affect the slope of the reaction-time function in the obtained manner. No doubt other formulations are possible. But formulations which assign the reaction-time differences to postperceptual stages of size estimation seem to us most likely to be correct.

\section{REFERENCES}

Broota, K. O., \& Epstein, W. The time it takes to make veridical size and distance judgments. Perception \& Psychophysics, 1973, 14, 358-364.

Carlson, V. R. Overestimation in size-constancy judgments. American Journal of Psychology, 1960, 73, 199-213.

Carlson, V. R. Size constancy judgments and perceptual compromise. Joumal of Experimental Psychology, 1962, 63. 68-73.

Carlson, V. R., \& Tassone, E. P. Independent size judgments at different distances. Journal of Experimental Psychology, 1967, 73, 491-498.

Cooper, L. A., \& Shepard, R. N. Chronometric studies of the rotation of mental images. In W. G. Chase (Ed.), Visual information processing. New York: Academic Press, 1973.

Epstein, W. Attitudes of judgment and the size-distance invariance hypothesis. Joumal of Experimental Psychology, 1963, 66, 78-83.

Epstein, W., Park, J., \& Casey, A. The current status of the size-distance invariance hypotheses. Psychological Bulletin, $1961,58,491-514$.

ShePARd, R. N., \& Metzler, J. Mental rotation of threedimensional objects. Science, 1971, 171, 701-703.

(Received for publication January 31, 1975; revision received June 16,1975 .) 